\title{
Effect of magnesium-salts on hydrogen peroxide bleaching of non-wood pulps
}

\author{
N. Das ${ }^{1 *}$, S K.Bose ${ }^{2}$ and D. Biswas ${ }^{2}$ \\ Interstate Paper Corporation 2366 Interstate Road, Riceboro, Georgia,31323, USA \\ ${ }^{2}$ Bangladesh Forest Research Institute, P.O.Box 273, Chittagong-4000, Bangladesh
}

\begin{abstract}
Transition metal ions present in pulp, cause wasteful decomposition of hydrogen peroxide, a pulp brightener, and thus significantly affect the delignification selectivity of hydrogen peroxide bleaching. The metal ions also affect the brightness and optical properties of pulp. The free radicals generated during the decomposition degrade carbohydrates resulting in lower viscosity and yield.

It is reported in the literature that magnesium sulfate successfully adsorbs transition metal ions and thus decrease their activity. This study dealt with the effect of $\mathrm{Mg}$ salts in hydrogen peroxide bleaching of jute caddies pulp. It was observed that prior bleaching treatments like chelation and acid washing of pulp were efficient in removing transition metal ions as indicated by lower consumption of hydrogen peroxide. However EDTA chelation seemed better compared to acid washing. The inclusion of Mg salts improved pulp brightness. The pulp viscosity was the highest with $0.3 \% \mathrm{Mg}$ addition for both treated kraft and soda-AQ pulps. Considering both pulp viscosity and pulp brightness, it appeared that a $0.3 \% \mathrm{Mg}$ dose on EDTA chelated pulp, was enough in hydrogen peroxide bleaching of pulps obtained from jute caddies.
\end{abstract}

Keywords: Jute caddies fibers; Hydrogen peroxide bleaching; Kraft; Magnesium salt; Soda-AQ

\section{Introduction}

The conservation of forests and growing environmental awareness has increased research interest in new renewable resources for pulp and paper mills. Bangladesh, a densely populated country, is already in short supply of forest resources in pulp mills, and is depending to a large extent on its non-wood fibre sources. A wide variety of non-wood plants, i.e., bamboo, bagasse, and straw, are used for paper making in many countries of the world. In Bangladesh extensive research on papermaking potential of jute fibre (Akhtaruzzaman, 1998; Akhtaruzzaman et al., 1988; Shafi et al., 1997) has identified the material as a promising pulp fibre source for various end uses.

Jute, a cheap, strong, durable fabric eminently suited for making sacks, bags, carpets, etc. has played a long historical role in the socio- economic development of Bangladesh. There is huge accumulation of unwanted waste during different production stages of the items from jute. This waste is a natural by- product of the industry. It is estimated that the loss in the shaker dust stage is about $6-9 \%$ of the total pro- duction of the industry. This shaker dust is a mixture of short unspinable fibers and dust with high oil content (jute batching oil). The droppings in the stages like under-card-draw from frames and looms are known as jute caddies, which are about $2-4 \%$ of the total production of the jute industry (Roy, 1982). There are about 105 jute mills (including 34 Twine mills) in Bangladesh (Anon, 1988). These mills are producing a large of amount of jute caddies which is mainly used as fuel for generating steam in the boilers, and in making cheaper cushions.

According to FAO there is a considerable scope for utilization of the waste generated during processing of jute, kenaf, coir and sisal (Anon, 1994). There is a high demand of packaging paper in the country. Jute caddies, a by-product of jute fibre, is already being used for the manufacture of the mid layer of a 3 ply duplex board. This potential fibre source could also be used for the manufacture of the top and bottom layers. The pulp produced from this fibre source is a bit darker in colour due to the presence of dirt and oily substances.

*Corresponding author e-mail: nihar.das@interstatepaper.com 
The colour of pulp could be improved with the use of hydrogen peroxide, a pulp brightener.

Previously, considerable research with hydrogen peroxide, but almost all of them dealt with either hardwood or softwood pulps (Loureiro, 2012; Lipierre et al., 2000; Lizi et al., 2011) There is not much study with non-wood fibres, especially jute caddies. It is well established that transition metals cause wasteful decomposition of hydrogen peroxide (Wojciak, 2006; Lizi et al., 2011). The free radicals generated during the decomposition degrade carbohydrates resulting in lower viscosity and yield. It is reported that sodium silicate and magnesium sulphate combination adsorbs transition metals and decrease their activity (Bose et al., 1998; Lapierre et.al., 1995; Potucek and Milichovsky, 2000). It is, therefore, imperative to study the effect of magnesium salts on deactivation of metal ions during peroxide bleaching of non-wood pulps and to optimize the $\mathrm{Mg}$ doses for maximum brightness and pulp viscosity.

\section{Materials and methods}

\section{Pulping experiments}

The air-dried ( $85.5 \%$ dry moisture content) jute caddies fibers equivalent to $250 \mathrm{~g}$ oven dried was cooked in small stainless steel autoclaves $(2 \mathrm{~L})$ heated in a temperature controlled air bath. Analytical grades of $\mathrm{NaOH}, \mathrm{Na}_{2} \mathrm{~S}$, and AQ were used. The following pulping parameters were maintained:

\section{-Liquor to fiber ratio, 7:1}

-Rise of temperature from room temperature to $80^{\circ} \mathrm{C}$ in 30 min and from 80 to $170^{\circ} \mathrm{C}$ in $60 \mathrm{~min}$;

-Cooking at maximum temperature $\left(170^{\circ} \mathrm{C}\right)$

-Active alkali, 14 - 18\% as $\mathrm{NaOH}$ in kraft and soda -AQ;

- A total H-factor of 2000 was used for pulping.

Different stages of delignification were achieved by varying the amount of effective alkali $(14 \%, 16 \%, 18 \%)$ both in kraft and soda-AQ pulping. The amount of AQ used in soda-AQ cooks were $0.1 \%$ calculated on oven dry material. The cooked material was washed with fresh water and then disintegrated. Screening was done on a flat vibratory screen with $0.38 \mathrm{~mm}$ slot. The screened pulp was pressed to remove excess water and stored in a refrigerator in polythene bags.

\section{Pulp analysis}

The yield and kappa number of pulp samples were determined (TAPPI Test Methods T236 cm-85). The percentage of lignin content in pulp was determined by multiplying the kappa number of pulp by a factor 0.15 (Toven et al., 2006)

\section{Preparation of pulps for hydrogen peroxide bleaching}

Two types of treatments likely acid treatment and chelation were given to reduce the free metal ions contents on the pulp prior hydrogen peroxide bleaching.

\section{a. Acid treatment of pulp}

$30 \mathrm{~g}$ of pulp on OD basis was taken in a stainless steel container and a sufficient amount of water was added so that the disintegrator moved freely in the slurry. The $\mathrm{pH}$ was then adjusted to 2.0 by adding $\mathrm{H}_{2} \mathrm{SO}_{4}$, to the continuously stirred pulp slurry. The slurry was stirred for an hour. Thereafter, the water was drained out and the pulp was washed thoroughly with distilled water.

\section{b. Chelation of pulp}

$30 \mathrm{~g}$ of pulp on OD basis was taken in a stainless steel container and a certain amount of water was added so that the disintegrator moves freely in the slurry. The $\mathrm{pH}$ was then adjusted to 4.3 with the addition of $\mathrm{H}_{2} \mathrm{SO}_{4}$ solution. Then $0.5 \%$ EDTA, based on OD pulp was added to the slurry maintaining the temperature at $60^{\circ} \mathrm{C}$ and stirred continuously for an hour. At the end of an hour the water was drained out and the pulp was washed thoroughly with fresh distilled water.

\section{Hydrogen peroxide bleaching}

The acid treated and the chelated pulps were taken in a poly bag. Then additional amount of water was added to have the slurry with $10 \%$ consistency. The $\mathrm{pH}$ of the slurry was adjusted to 11.0 with addition of $\mathrm{NaOH}$ solution. The different doses of $\mathrm{MgSO}_{4}, 7 \mathrm{H}_{2} \mathrm{O}$ followed by $2 \% \mathrm{H}_{2} \mathrm{O}_{2}$ solution, (all based on OD pulp) were added to the pulp which was then mixed thoroughly. The poly bag was then sealed and placed in a water bath maintained at $80^{\circ} \mathrm{C}$ for 2 hours with occasionally mixing. At the end of the reaction, the poly bags were taken out. The liquor was titrated to measure the residual $\mathrm{H}_{2} \mathrm{O}_{2}$. A portion of the liquor was used to measure the end $\mathrm{pH}$. Thereafter, the water was drained out and the pulp was washed thoroughly with distilled water. The viscosity 
and brightness of pulps were determined according to Tappi test methods T230 om-89 and T452 om-92 respectively.

\section{Estimation of residual $\mathrm{H}_{2} \mathrm{O}_{2}$}

$20 \mathrm{~mL}$ of $4 \mathrm{~N}$ sulfuric acid was taken in a $250 \mathrm{~mL}$ conical flask and $25 \mathrm{~mL} 10 \% \mathrm{KI}$ solution was added to it. $5 \mathrm{~mL}$ of the spent liquor sample was added and titrated against $0.1 \mathrm{~N}$ $\mathrm{Na}_{2} \mathrm{~S}_{2} \mathrm{O}_{3}$ solution using starch as the indicator.

\section{Results and discussion}

Pulp yield

Pulping of jute caddies was done at different total alkali charge to obtain various levels of delignification. The pulping results are shown in Table I. It was found that delignification increased with the increase of alkali charge. The delignification was slightly better with soda-AQ compared to kraft at low alkali dose.. The pulp yield was even higher with soda-AQ.
The delignification results are given in Table II. The table shows that the amount of lignin removed did not vary either for the change in active alkali or for the change in pulping processes. However, the amount of carbohydrate removed was lower in case of soda-AQ process compared to kraft process. This resulted in higher selectivity ratio for soda-AQ process compared to kraft. The selectivity values remained the same for kraft process. However, it changed in soda-AQ pulping. It was the highest with $14 \%$ active alkali. The result was obvious as AQ acted as a nucleophile and thus, enhanced the rate of delignification. This increased delignification reduced the carbohydrate loss that resulted in higher pulp yield.

\section{Hydrogen peroxide bleaching}

The pulp was bleached using hydrogen peroxide, as a brightener, at $80^{\circ} \mathrm{C}$ for two hours. The pulp consistency was $10 \%$. The chemical doses were $0.3,0.5$ and $1.0 \%$ of $\mathrm{MgSO}_{4}, 7 \mathrm{H}_{2} \mathrm{O}$ and $2 \%$ of $\mathrm{H}_{2} \mathrm{O}_{2}$, all calculated on oven dry pulp. The results,

Table I. Pulp yield and lignin content of various pulps* \#

\begin{tabular}{lcccccc}
\hline $\begin{array}{l}\text { Pulping } \\
\text { processes }\end{array}$ & $\begin{array}{c}\text { Active Alkali } \\
\text { (as NaOH) } \%\end{array}$ & $\begin{array}{c}\text { AQ } \\
\%\end{array}$ & Kappa No. & $\begin{array}{c}\text { Pulp yield } \\
\%\end{array}$ & $\begin{array}{c}\text { Lignin content } \\
\text { of pulp } \%\end{array}$ & $\begin{array}{c}\text { Delignification } \\
\%\end{array}$ \\
\hline kraft & 14.0 & 0.0 & 16.9 & 50.8 & 2.54 & 90.6 \\
& 16.0 & 0.0 & 13.0 & 50.0 & 1.95 & 92.9 \\
& 18.0 & 0.0 & 11.8 & 49.7 & 1.77 & 93.6 \\
soda-AQ & 14.0 & 0.1 & 13.7 & 57.8 & 2.06 & 91.3 \\
& 16.0 & 0.1 & 11.9 & 55.0 & 1.78 & 92.8 \\
& 18.0 & 0.1 & 11.3 & 53.9 & 1.70 & 93.3 \\
\hline
\end{tabular}

* Lignin content of the original material $=13.7 \%$

\# Carbohydrate content of the original material $=81.3 \%$

The kappa number of the kraft pulps decreased sharply with the increase of active alkali. However, in case of soda-AQ process the kappa number changes were not that big. This might be due to redeposition of dissolved lignin on residual lignin (Francis et al., 2005). The situation was quite opposite in case of pulp yield. In soda-AQ process the drop in pulp yield with the increase of active alkali was higher than that of kraft process. Various researchers reported the same observation in the past (Shafi et al., 1994; Akhtaruzzaman and Shafi, 1995).

\section{Delignification selectivity}

Selectivity is defined as a ratio between the amounts of lignin removed over the amount of carbohydrate removed. for both treated and untreated pulps, were shown in Table III and IV and Fig. 1 and 2.

The bleached pulp yield was the highest with the untreated kraft compared to both chelated and acid washed kraft pulps (Table III and Fig. 1). The bleached pulp yield increased with the increase of $\mathrm{Mg}$ doses with the exception of acid washed pulp where the yield decreased by 1.3 percent points. This could be due to the removed of $\mathrm{Mg}^{2+}$ during acid treatment and the amount of $\mathrm{Mg}^{2+}$ added after words was not enough. The pulp viscosity was the highest with $0.3 \% \mathrm{Mg}$ charge. Wojciak (2002) reported similar results. The consumption of peroxide was the highest with untreated pulp as it contained higher percentages of metal ions compared to both 
Table II. Selectivity of pulping processes

\begin{tabular}{|c|c|c|c|c|c|c|c|}
\hline $\begin{array}{l}\text { Pulping } \\
\text { processes }\end{array}$ & $\begin{array}{c}\text { Active alkali } \\
\text { (as } \mathrm{NaOH} \text { ) } \\
\%\end{array}$ & $\begin{array}{l}\text { AQ } \\
(\%)\end{array}$ & $\begin{array}{c}\text { Kappa no. } \\
(\%)\end{array}$ & $\begin{array}{l}\text { Pulp yield } \\
\qquad \%)\end{array}$ & $\begin{array}{l}\text { Lignin removed } \\
\text { (original raw } \\
\text { material basis }(\mathrm{g})\end{array}$ & $\begin{array}{c}\text { Carbohydrate removed } \\
\text { (original raw } \\
\text { material basis }(\mathrm{g})\end{array}$ & $\begin{array}{c}\text { Selectivity } \\
\text { ratio }\end{array}$ \\
\hline \multirow{3}{*}{ kraft } & 14.0 & 0.0 & 16.9 & 50.8 & 31.0 & 79.5 & 0.39 \\
\hline & 16.0 & 0.0 & 13.0 & 50.0 & 31.8 & 80.7 & 0.39 \\
\hline & 18.0 & 0.0 & 11.8 & 49.7 & 32.1 & 81.2 & 0.39 \\
\hline \multirow{3}{*}{ soda-AQ } & 14.0 & 0.1 & 13.7 & 57.8 & 31.3 & 61.7 & 0.51 \\
\hline & 16.0 & 0.1 & 11.9 & 55.0 & 31.8 & 68.2 & 0.47 \\
\hline & 18.0 & 0.1 & 11.3 & 53.9 & 32.0 & 75.5 & 0.42 \\
\hline
\end{tabular}

* g lignin removed/g carbohydrate removed.

Table III. Effect of magnesium sulfate application on hydrogen peroxide bleaching of kraft pulp

\begin{tabular}{lcccccccc}
\hline & \multicolumn{3}{c}{ Untreated kraft } & \multicolumn{3}{c}{ Chelated kraft } & \multicolumn{2}{c}{ Acid washed kraft } \\
\hline $\mathrm{MgSO}_{4}, 7 \mathrm{H}_{2} \mathrm{O} \%$ on pulp & 0.3 & 0.5 & 1.0 & 0.3 & 0.5 & 1.0 & 0.3 & 0.5 \\
Yield, \% & 98.6 & 98.4 & 98.9 & 93.5 & 94.2 & 94.2 & 90.6 & 89.3 \\
Kappa No & 12.8 & 13.0 & 13.4 & 11.0 & 10.0 & 10.0 & 11.0 & 10.0 \\
Viscosity, cp & 10.9 & 7.5 & 8.3 & 8.6 & 6.3 & 6.5 & 8.4 & 7.2 \\
Elrepho Brightness, \% & 34.3 & 35.5 & 33.7 & 38.4 & 39.6 & 41.0 & 37.4 & 41.7 \\
Consumption $\mathrm{H}_{2} \mathrm{O}_{2}, \%$ & 95.6 & 97.8 & 97.8 & 50.0 & 56.1 & 60.5 & 50.0 & 47.0 \\
End pH & 8.8 & 9.0 & 8.8 & 11.3 & 10.9 & 11.3 & 8.2 & 8.5 \\
\hline
\end{tabular}

(Unbleached pulp kappa no- 16.9, Elrepho Brightness- 28.5\%, kraft pulp viscosity- 17.3)

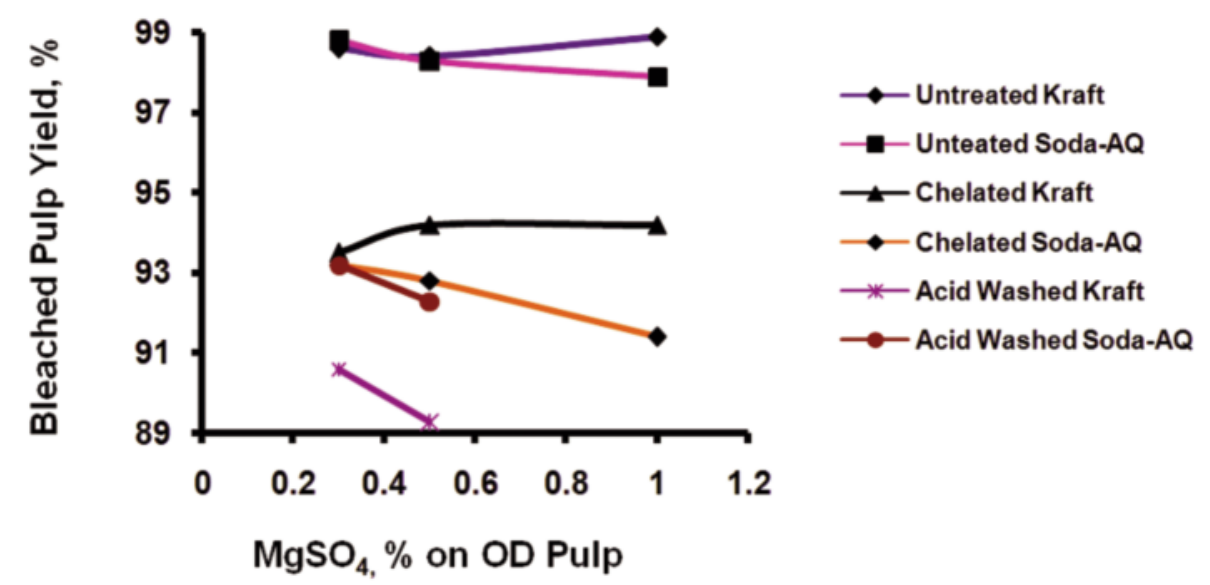

Fig. 1. Effect of Mg dose on bleached pulp yield

chelated and acid washed pulps. There was severe viscosity loses in all the cases. After bleaching untreated pulp brightness was lower compared to the treated pulps.

It is also observed that end $\mathrm{pHs}$ were higher with the addition of magnesium salts. Bose et al. (1998) reported similar observations. The results suggested that in order to get better pulp yield with acceptable viscosity $\mathrm{MgSO}_{4}, 7 \mathrm{H}_{2} \mathrm{O}$ dose of $0.3-0.5 \%$ (on OD pulp) is beneficial.

In case of soda-AQ pulp the yield and viscosity decreased gradually (Table IV and Fig. 1) with the increase of $\mathrm{Mg}$ charge. The pulp viscosity was the highest with $0.3 \% \mathrm{Mg}$ charge. In all the cases, $0.3 \% \mathrm{Mg}$ dose showed the best performance. 
Table IV. Effect of magnesium sulfate application on hydrogen peroxide bleaching of soda-AQ pulp

\begin{tabular}{lcccccccc}
\hline & \multicolumn{3}{c}{ Untreated soda-AQ } & \multicolumn{3}{c}{ Chelated soda-AQ } & \multicolumn{2}{c}{ Acid washed soda- AQ } \\
\hline $\mathrm{MgSO}_{4} \cdot 7 \mathrm{H}_{2} \mathrm{O}$ & & & & & & & \\
$\%$ on pulp & 0.3 & 0.5 & 1.0 & 0.3 & 0.5 & 1.0 & 0.3 & 0.5 \\
Yield, \% & 98.8 & 98.3 & 97.9 & 96.6 & 92.8 & 91.4 & 93.2 & 92.3 \\
Kappa No & 10.6 & 10.3 & 10.0 & 9.4 & 9.0 & 9.0 & 7.8 & 7.6 \\
Viscosity, cp & 11.0 & 6.2 & 5.9 & 10.3 & 9.2 & 8.1 & 6.1 & 5.0 \\
Elrepho Brightness, \% & 40.6 & 43.3 & 42.0 & 46.0 & 46.4 & 47.4 & 43.4 & 46.4 \\
Consumption $\mathrm{H}_{2} \mathrm{O}_{2}, \%$ & 98.0 & 98.0 & 98.0 & 87.0 & 85.0 & 82.0 & 47.0 & 41.0 \\
End pH & 9.1 & 10.3 & 10.6 & 11.5 & 11.3 & 11.5 & 8.3 & 9.0 \\
\hline
\end{tabular}

(Unbleached pulp kappa No 13.7, Elrepho Brightness-31.6\%, soda-AQ pulp viscosity- 11.5)

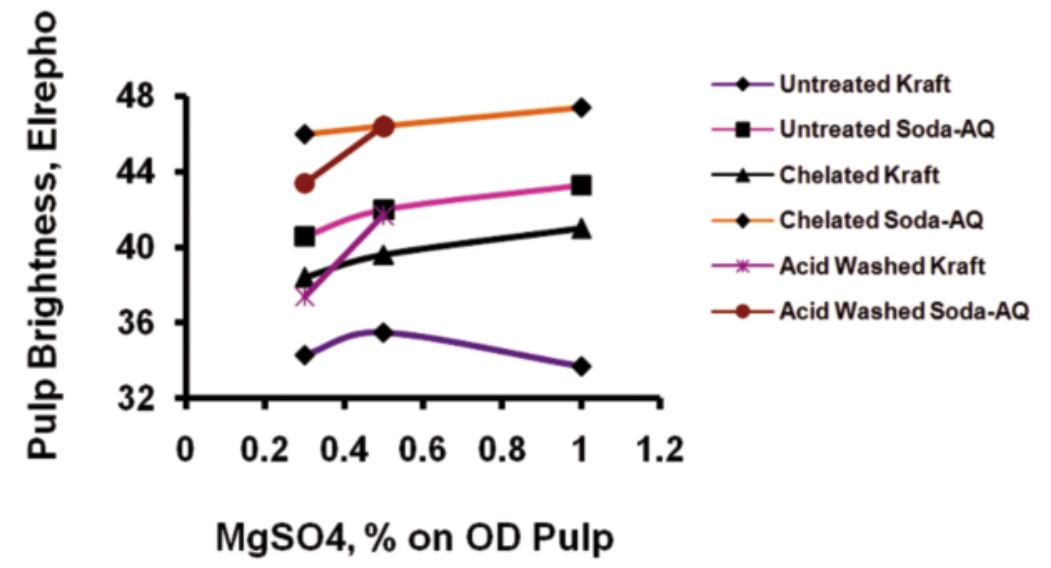

Fig. 2. Effect of Mg dose on bleached pulp brightness

The consumption of peroxide was the highest with untreated pulp as it contained higher percentages of metal ions compared to both chelated and acid washed pulps. Presence of higher amount of metal ions resulted in fast decomposition of hydrogen peroxide. On bleaching, untreated pulp brightness was lower compared to the treated pulps (Fig. 2). There was viscosity loss in all the cases (Table III and IV).

\section{Conclusion}

The selectivity ratio in kraft and soda-AQ pulp from jute caddies was highest with $14 \%$ soda-AQ pulping. The reason was that the amount of lignin removed was almost the same with all alkali doses, but the amount of carbohydrate removed was the lowest with $14 \%$ soda-AQ pulping. The result is obvious as AQ acted as a nucleophile and thus, enhanced the rate of delignification. This increased delignification and reduced the carbohydrate loss that resulted in higher delignification selectivity.
Hydrogen peroxide bleaching of kraft and soda-AQ pulps showed that both chelation and acid-treatment of pulps were efficient in removing transition metal ions. However chelation was better in consideration of the pulp viscosity and pulp brightness. The inclusion of Mg salts improved pulp brightness. The brightness was higher with treated pulps. Among the three doses of $\mathrm{Mg}$ addition, the pulp viscosity was highest with $0.3 \% \mathrm{Mg}$ both with kraft and soda-AQ pulps. Considering both pulp viscosity and pulp brightness, it appeared that a $0.3 \% \mathrm{Mg}$ dose on EDTA chelated OD pulp, was enough for hydrogen peroxide bleaching of pulps obtained from jute caddies.

\section{References}

Akhtaruzzaman AFM (1998), Strategies for jute pulping. Pulping Conference, October 25-29, Queen Elizabeth Hotel, Montreal, Quebec, Canada. TAPPI press. pp 661-668. 
Akhtaruzzaman AFM and Shafi M (1995), Pulping of jute, Tappi journal 78(2): 106-112.

Akhtaruzzaman AFM, Siddique AB, Bose SK, Das P, Chowdhury AR and Das MM (1988), Neutral Sulphite Anthraquinone pulping of jute. Tappi Pulping Conference, New Orleans, LA, USA Oct. 30-Nov. 2. Proceedings, Book 2. pp 475-484.

Anon. (1988), Task force Report, a study on the utilization of jute cuttings/lower grade jute for paper making. Ministry jute, Govt. of the Peoples Republic of Bangladesh, Dhaka, 132.

Anon. (1994), FAO Recommendation on export group meeting on diversified application of bio-resources such as jute, kenaf, coir, sisal and allied fibers held in Bangladesh, India, 5-7 October, ESC: JU/EGM 94/Rec/ II .

Bose SK, Granzow SG, Pugliese DH, Francies RC and Evans TD (1998), Yield after pressurized peroxide(PO) bleaching of softwood kraft pulps. Proceedings. TAPPI Pulping Conference. Tappi press, Atlanta 1585.

Francies RC, Bose SK, Shin NH, Omori S and Brown AF (2005), Bleached hardwood pulps by the soda/ AQ and MAQ processes. Session 74, Tappi Engineering, Pulping, and Environmental Conf., Philadelphia, August 28.

Lapierre L, Berry RM and Bouchard J (2000), The effects of the order of chemical addition on the peroxide bleaching of an oxygen delignified softwood kraft pulp, Holzforschung 3: 279-286.

Lapierre L, Bouchard J, Berry RM and Vanlierop B (1995), Chelation prior to Hydrogen peroxide bleaching of kraft pulps- An overview, Journal of Pulp and Paper Science 21(8): J268-J273.
Lizi Li, Sanghoon Lee; Haklae Lee and Hye Jung Youn (2011), $\mathrm{H}_{2} \mathrm{O}_{2}$ bleaching of pulp with adsorbed xylan, Bio resources 6(1): 721-736.

Loureiro PEG (2012), On the role of xylan in the final bleaching of Eucalyptus globulus kraft pulps. A. Dissertation of integrated Master in Chemical Engineering, Universidade of Coimbra. p 49.

Potucek F and Milichovsky M (2000), Kraft pulp bleaching with hydrogen peroxide and peracetic acid, Chem. Papers 54(6a): 406-411.

Roy AK (1982), Jute caddies as raw material for paper making, Indian Pulp and Paper, 36,22.

Shafi M, Mian AJ and Aktaruzzaman AFM (1994), Neutral Sulphite Anthraquinone pulping of jute stick, Bangladesh Journal of Forest Science 23(2): 86-91.

Shafi M, Mian A J and Akhtaruzzaman AFM (1997), Pulping of unretted jute fiber by neutral sulphite anthraquinone (NS-AQ) process, Journal of Tropical Forest Products 3(1): 97-104.

Toven K, Gelleratedt G, Kleppe P and Moe S (2002), Use of chlorine dioxide and ozone in combination in prebleaching, Journal of Pulp and Paper Science 28(9): 305-310.

Wójciak A (2002), The effect of pH of hydrogen peroxide solution on kraft pine pulp delignification, Fol, For. Pol. B 33: 33.

Wójciak A (2006), Influence of Mg addition on hydrogen peroxide bleaching of the acid treated pinewood kraft pulp, Electronic Journal of Polish Agricultural Universities, Wood Technology 9(1): 23.

Received: 22 February 2016; Revised: 03 March 2016; Accepted:24 April 2016. 